\title{
Cardioprotection of cortistatin against isoproterenol-induced myocardial injury in rats
}

\author{
Wenjia Chen $^{1 \#}$, Juan Liang ${ }^{2 \#}$, Yu Fu ${ }^{1}$, Yuanyuan Jin ${ }^{1}$, Runan Yan $^{1}$, Jinyu Chi ${ }^{1}$, Wenxiu Liu ${ }^{1}$, Yue Liu ${ }^{1}$, \\ Xinhua Yin ${ }^{1}$ \\ ${ }^{1}$ Department of Cardiology, the First Affiliated Hospital of Harbin Medical University, Harbin 150001, China; ${ }^{2}$ Department of Cardiology, Sun Yat- \\ sen Memorial Hospital of Sun Yat-sen University, Guangzhou 510120, China \\ Contributions: (I) Conception and design: All authors; (II) Administrative support: All authors; (III) Provision of study materials or patients: All \\ authors; (IV) Collection and assembly of data: All authors; (V) Data analysis and interpretation: All authors; (VI) Manuscript writing: All authors; (VII) \\ Final approval of manuscript: All authors. \\ "These authors contributed equally to this work. \\ Correspondence to: Yue Liu, MD, PhD; Xinhua Yin, MD, PhD. Department of Cardiology, the First Affiliated Hospital of Harbin Medical University, \\ No. 23, Youzheng Street, Nangang District, Harbin 150001, China. Email: liuyue198002@163.com; xinhua_yin@163.com.
}

Background: The present study was designed to examine whether cortistatin (CORT) could protect rats from myocardial injury induced by subcutaneously injecting isoproterenol (ISO) and to clarify the possible mechanisms.

Methods: Male Sprague-Dawley (SD) rats were placed at random into four groups: the control group, the ISO group, the ISO + CORT $25 \mu \mathrm{g} /(\mathrm{kg} \cdot \mathrm{d})$ group, and the ISO + CORT $50 \mu \mathrm{g} /(\mathrm{kg} \cdot \mathrm{d})$ group. Rat models of myocardial injury were established with the subcutaneous (s.c.) injections of $85 \mathrm{mg} / \mathrm{kg}$ ISO for 2 days. In the ISO+ CORT $25 \mu \mathrm{g} /(\mathrm{kg} \cdot \mathrm{d})$ group and ISO+CORT $50 \mu \mathrm{g} /(\mathrm{kg} \cdot \mathrm{d})$ group, rats were given s.c. injections of CORT $25 \mu \mathrm{g} /(\mathrm{kg} \cdot \mathrm{d})$ and CORT $50 \mu \mathrm{g} /(\mathrm{kg} \cdot \mathrm{d})$ on the day before ISO, 3 days, respectively. Serum malondialdehyde (MDA) content, lactate dehydrogenase (LDH) activity, and creatine kinase isoenzyme (CK$\mathrm{MB})$ activity were measured by corresponding test kits. Western blot was applied to evaluate the expression of endoplasmic reticulum stress-related protein glucose regulatory protein 78 (GRP78), enhancer-binding protein homologous protein (CHOP), cysteinyl aspartate specific proteinase-12 (caspase-12), LC3-II, Beclin-1, and p62 in the rat myocardium.

Results: CORT alleviated the increased enzyme activities of serum LDH and CK-MB, and content of MDA (a typical marker of lipid peroxidation) in rats induced by ISO. CORT also prevented pathological myocardial injury in rats induced by ISO. Moreover, CORT attenuated the increased protein levels of GRP78, CHOP, and caspase-12, and reduced the increase of LC3-II, LC3-II/I, Beclin-1, and p62 in rats induced by ISO.

Conclusions: These data demonstrate that CORT can attenuate ISO-induced acute myocardial injury in rats likely by reducing lipid peroxidation, and inhibiting endoplasmic reticulum stress and autophagy. This supports CORT as a potentially being a new target for preventing and treating myocardial injury and its related disease.

Keywords: Cortistatin (CORT); acute myocardial injury; autophagy; endoplasmic reticulum stress

Submitted Sep 16, 2019. Accepted for publication Feb 04, 2020.

doi: $10.21037 /$ atm.2020.02.93

View this article at: http://dx.doi.org/10.21037/atm.2020.02.93 


\section{Introduction}

Although an increase in public awareness and the improvement of therapeutic strategies including the use of antiplatelet drugs, thrombolytic drugs, and percutaneous coronary intervention, acute myocardial infarction (AMI) remain as one of the major causes of morbidity and mortality in patients with ischemic heart diseases (IHD) worldwide. Myocardial injury, including AMI, is a common feature of IHD. Although the pathogenesis of myocardial injury remains unclear, it is involved in multiple mechanisms, such as endoplasmic reticulum stress (ERS), oxidative stress, apoptosis, autophagy, and inflammation (1). There is a lack of consensus concerning the best therapeutic strategies, even though the mechanism of AMI has been extensively studied. Therefore, it is important and urgent to investigate the pathogenic mechanism of myocardial injury and to explore new myocardial protection strategies in the field of cardiology.

An increasing number of studies have indicated endogenous bioactive peptides play an important role in reducing myocardial injury and exerting cardioprotective effect (2). Cortistatin (CORT) is a new endogenous bioactive peptide originally found in the cerebral cortex and hypothalamus (3). Further studies indicated that CORT was widely expressed in the nervous, endocrine, and immune systems, and in areas such as the brain cortex, stomach, pancreas, monocytes, macrophages, and dendritic cells (3). CORT has been shown to exert multiple biological effects, including increased sleep, anti-nociception, antiinflammation, induction of immune tolerance, and regulation of endocrine and metabolism, through activating somatostatin receptors (SSTRs) and/or growth hormone secretagogue receptor 1a (GHSR1a) $(3,4)$.

In recent years, increasing importance has been attached to the protective role of CORT in the development of cardiovascular diseases since CORT and its receptors are widely expressed in heart and blood vessels (5). Several studies have indicated that CORT can attenuate the proliferation and migration of vascular smooth muscle cells (VSMC) (6,7), alleviate autoimmune myocarditis in mice immuno-induced by a fragment of cardiac myosin (8), and inhibit atherosclerosis in ApoE-deficient mice fed western-style diets (9). Our experimental results showed that CORT could inhibit vascular calcification in rats in vivo and in vitro $(10,11)$, and suppress myocardial apoptosis and activation of cardiac fibroblasts in rats during sepsis $(12,13)$. In the previous study, we also found CORT could improve heart function in rat myocardial infarction induced by left anterior descending coronary artery ligation (14). However, the role and the underlying mechanisms of CORT in the development of myocardial injury remain obscure.

Therefore, the present study was designed to examine whether CORT could protect rats from myocardial injury induced by subcutaneously injecting isoproterenol and to clarify the possible mechanisms. It is hoped that this will provide a novel target for the prevention and treatment of myocardial injury and its related diseases.

\section{Methods}

\section{Animals and materials}

Male Sprague-Dawley (SD) rats $(200 \pm 20 \mathrm{~g})$ were provided by The Second Affiliated Hospital of Harbin Medical University. All experimental protocols conformed to the Animal Management Rule of the People's Republic of China (Ministry of Health, China, document no. 55, 2001), and the Animal Care Committee of Harbin Medical University Health Science Center.

The rat CORT-14 was obtained from Phoenix Pharmaceuticals Inc. (Belmont, CA, USA). Isoproterenol (ISO) was purchased from Sigma (St. Louis, MO, USA). Rabbit polyclonal anti-glucose regulatory protein 78 (GRP78), anti-cysteinyl aspartate specific proteinase-12 (Caspase-12), and anti-LC3 antibodies were obtained from Abcam Inc. (Cambridge, MA, USA). Rabbit monoclonal antibody to Beclin-1 was purchased from Cell Signaling Technology Inc. (MA, USA). The creatine kinase isoenzyme (CK-MB) assay kit, lactate dehydrogenase (LDH) assay kit, and malondialdehyde (MDA) assay kit were obtained from the Nanjing Jiancheng Bioengineering Company (Nanjing, China). Rabbit polyclonal antibodies to CCAAT/enhancerbinding proteins (C/EBP) homologous protein (CHOP), and p62, mouse anti-GAPDH monoclonal antibody was obtained from ABclonal Technology (Wuhan, China). Peroxidase-conjugated goat anti-rabbit immunoglobulin G and rabbit anti-mouse immunoglobulin $\mathrm{G}$ were purchased from ZSGB-BIO (Beijing, China).

\section{Induction of myocardial injury in a rat model and animal groups}

All rats were kept at room temperature $\left(24 \pm 1{ }^{\circ} \mathrm{C}\right)$, with humidity at $50-55 \%$, in a $12 / 12 \mathrm{~h}$ light/dark ratio with ad libitum access to standard rat feed and water. They were 
randomly divided into four groups (8 rats in each group): (I) control group, and rats received subcutaneous (s.c.) injection with equal volume saline daily for 2 days; (II) ISO group, a rat experimental model of myocardial injury was induced by ISO as described previously (15) with rats receiving s.c. injection with ISO $85 \mathrm{mg} /(\mathrm{kg} \cdot \mathrm{d})$ for 2 days; (III) $\mathrm{ISO}+$ CORT $25 \mu \mathrm{g} /(\mathrm{kg} \cdot \mathrm{d})$ group and ISO + CORT $50 \mu \mathrm{g} /(\mathrm{kg} \cdot \mathrm{d})$ group, rats received s.c. injection with CORT $25 \mu \mathrm{g} /(\mathrm{kg} \cdot \mathrm{d})$ and CORT $50 \mu \mathrm{g} /(\mathrm{kg} \cdot \mathrm{d})$ for 3 days, respectively, which began on the day before ISO treatment. All animals fasted for $12 \mathrm{~h}$ before they were deeply anesthetized by $10 \%$ chloral hydrate $(3 \mathrm{~mL} / \mathrm{kg}$, intraperitoneal administration). Then, blood samples were collected and centrifuged at 3,500 $\mathrm{rpm}$ for $15 \mathrm{~min}$ for separating serum that was stored at $-20^{\circ} \mathrm{C}$ for further analysis. At the same time, hearts were removed and saved for testing as required.

\section{Hematoxylin and eosin (HE) staining}

After removing large blood vessels and epicardial adipose tissue, hearts were washed with cold saline and blotted dry with filter paper. The heart was cut into two halves from the central plane of the left ventricle. After the apexes were fixed for $24 \mathrm{~h}$ in $4 \%$ paraformaldehyde, they were dehydrated and then embedded in paraffin, and cut into 5- $\mu$ m-thick sections. These sections were stained with $\mathrm{HE}$, and then examined and photographed under a light microscope for pathomorphological changes.

\section{Measurement of biochemical parameters}

Enzyme activities of LDH and CK-MB and MDA content were measured in the serum of rats with the use of corresponding kits obtained from the Nanjing Jiancheng Bioengineering Company according to the manufacturer's protocols.

\section{Western blotting analysis}

Western blot analysis was performed as previously described (11). In brief, tissue samples were homogenized at $4{ }^{\circ} \mathrm{C}$ and lysed on ice for $15 \mathrm{~min}$ with 10 volumes of tissue lysis buffer, followed by centrifugation $\left(4^{\circ} \mathrm{C}, 13,500 \mathrm{rpm}\right)$ for $20 \mathrm{~min}$. The supernatants were used as protein samples. Protein concentrations were determined with the use of the enhanced bicinchoninic acid (BCA) Protein Assay kit (Beyotime, Nantong, China), Protein samples (50 $\mu \mathrm{g})$ were separated by $10 \%$ sodium dodecyl sulfate-polyacrylamide gel electrophoresis (SDS-PAGE) and transferred to polyvinylidene fluoride (PVDF) membrane. The PVDF membrane was incubated with $5 \%$ non-fat dried milk for 1 h at $37^{\circ} \mathrm{C}$. Then, the membranes were incubated overnight at $4{ }^{\circ} \mathrm{C}$ with primary antibodies: anti-GRP78 $(1: 1,000)$, anti-Caspase-12 (1:1,000), anti-CHOP (1:500), anti-p62 (1:500), anti-Beclin-1 $(1: 1,000)$, anti-LC3 $(1: 1,000)$, and anti-glyceraldehyde-3phosphate dehydrogenase (GAPDH) (1:20,000), followed by the secondary antibody for $1 \mathrm{~h}$ at $37^{\circ} \mathrm{C}$. They were visualized by the enhanced chemilumescent (ECL) detection system and analyzed by Image Lab software. Protein levels of GRP78, Caspase-12, CHOP, p62, Beclin-1 and LC3 were normalized to that of GAPDH.

\section{Statistical analysis}

All data were presented as mean \pm standard error of mean (SEM). Statistical comparison between groups was performed with one-way analysis of variance (ANOVA), followed by Tukey's test using GraphPad PRISM 7 (Graphpad Inc., La Jolla, CA, USA). A P value $<0.05$ was considered statistically significant.

\section{Results}

\section{CORT alleviated serum markers of ISO-induced myocardial injury and lipid peroxidation in rats}

Clinical and basic studies have shown that LDH and CKMB enzyme activities are regarded as classical markers of myocardial injury. Compared with the control group, serum activities of LDH and CK-MB were significantly increased in the ISO group $(6,661 \pm 1,159$ vs. 3,827 $\pm 1,327 \mathrm{U} / \mathrm{L}$, $\mathrm{P}<0.0001 ; 167.20 \pm 37.15$ vs. 47.68 $16.76 \mathrm{U} / \mathrm{L}, \mathrm{P}<0.0001$, respectively) (Figure $1 A, B)$. Both $25 \mu \mathrm{g} /(\mathrm{kg} \cdot \mathrm{d})$ CORT and $50 \mu \mathrm{g} /(\mathrm{kg} \cdot \mathrm{d})$ obviously decreased serum LDH activity $(4,474 \pm 698.3$ vs. 6,661 $\pm 1,159 \mathrm{U} / \mathrm{L}, \mathrm{P}<0.05 ; 3,635 \pm 528.9$ vs. $6,661 \pm 1,159 \mathrm{U} / \mathrm{L} \mathrm{P}<0.01$, respectively) and $\mathrm{CK}-\mathrm{MB}$ activity

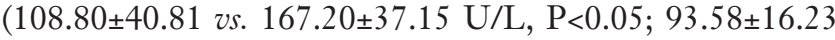
vs. $167.20 \pm 37.15 \mathrm{U} / \mathrm{L}, \mathrm{P}<0.01$, respectively) in rats of the ISO + CORT $25 \mu \mathrm{g} /(\mathrm{kg} \cdot \mathrm{d})$ group and ISO + CORT $50 \mu \mathrm{g} /(\mathrm{kg} \cdot \mathrm{d})$ group compared with those of the ISO group (Figure $1 A, B)$. However, there was no statistically significant difference in serum $\mathrm{LDH}$ and $\mathrm{CK}-\mathrm{MB}$ activity between the ISO + CORT $25 \mu \mathrm{g} /(\mathrm{kg} \cdot \mathrm{d})$ group and ISO + CORT $50 \mu \mathrm{g} /(\mathrm{kg} \cdot \mathrm{d})$ group (Figure $1 A, B)$.

MDA has been identified as a typical marker of lipid peroxidation. The content of MDA was higher in the 

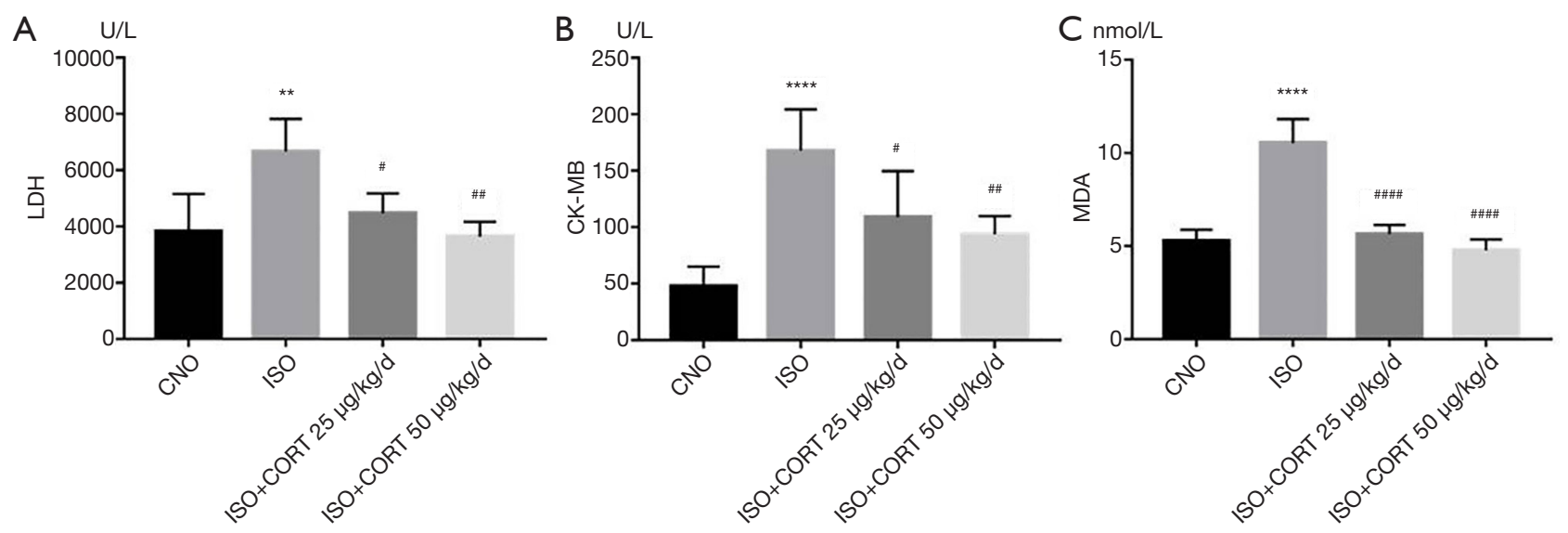

Figure 1 The serum levels of LDH, CK-MB and MDA in rats of each group. (A) CORT suppressed the ISO-induced increases of LDH activity in rats; (B) CORT suppressed the increase of CK-MB activity in rats induced by ISO; (C) CORT reduces the increased level of MDA content in serum of rats induced by ISO. Rats in the ISO + CORT25 $\mu \mathrm{g} / \mathrm{kg} / \mathrm{d}$ group and ISO + CORT50 $\mu \mathrm{g} / \mathrm{kg} / \mathrm{d}$ group were injected with different doses of CORT (25 and $50 \mu \mathrm{g} / \mathrm{kg}$, respectively) for three days. Data are presented as means $\pm \mathrm{SEM}(\mathrm{n}=5)$, ${ }^{* *}, \mathrm{P}<0.01$ and ${ }^{* * * *}$, $\mathrm{P}<0.0001$ vs. CON group; ", $\mathrm{P}<0.05$, \#, $\mathrm{P}<0.01$, and ${ }^{\# \# \#, ~} \mathrm{P}<0.0001$ vs. ISO group. LDH, lactate dehydrogenase; CK-MB, creatine kinase isoenzyme; MDA, malondialdehyde; CON, control; ISO, isoproterenol; CORT, cortistatin.

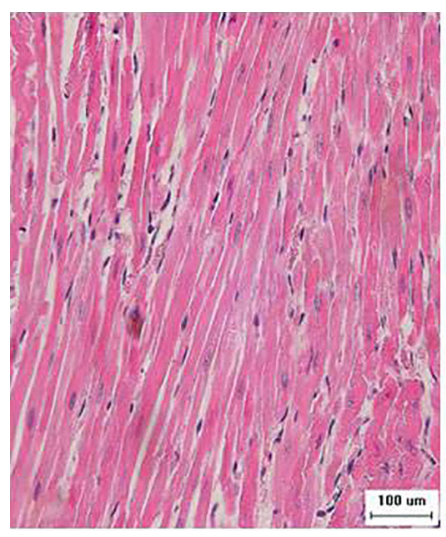

$\mathrm{CNO}$

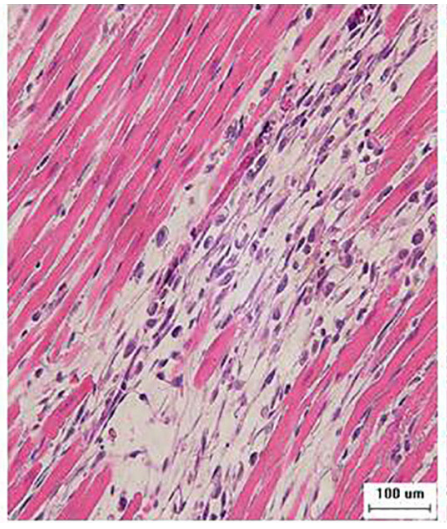

ISO

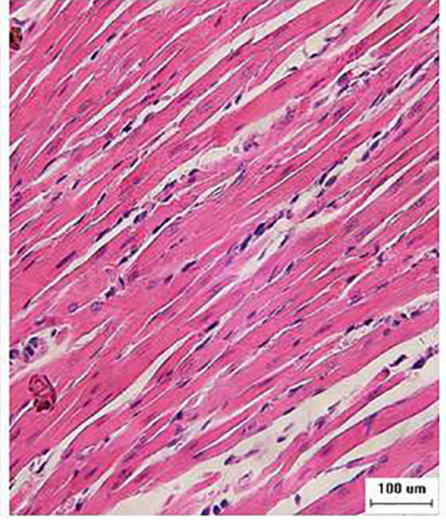

ISO+CORT $25 \mu \mathrm{g} / \mathrm{kg} / \mathrm{d}$

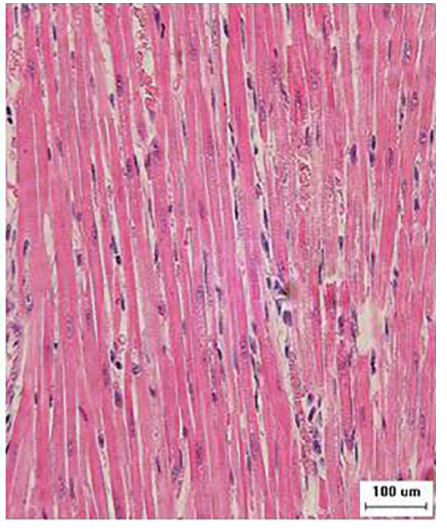

ISO+CORT $50 \mu \mathrm{g} / \mathrm{kg} / \mathrm{d}$

Figure 2 HE staining change of myocardial tissue in each group of rats (400×, scale is $100 \mu \mathrm{m})$. CON, control; ISO, isoproterenol; CORT, cortistatin.

ISO group than that in the control group $(10.53 \pm 1.29 v s$. $5.23 \pm 0.60 \mathrm{nmol} / \mathrm{mL}, \mathrm{P}<0.01$ ) (Figure 1 C). Different doses of CORT significantly reduced serum content of MDA in rats of the ISO + CORT $25 \mu \mathrm{g} /(\mathrm{kg} \cdot \mathrm{d})$ group and the ISO + CORT $50 \mu \mathrm{g} /(\mathrm{kg} \cdot \mathrm{d})$ group compared with the ISO group, (5.64 \pm 0.49 vs. $10.53 \pm 1.29 \mathrm{nmol} / \mathrm{mL}, \mathrm{P}<0.0001 ; 4.76 \pm 0.59$ vs. $10.53 \pm 1.29 \mathrm{nmol} / \mathrm{mL}, \mathrm{P}<0.0001$, respectively) (Figure 1C). However, there was no statistically significant difference in serum MDA between the ISO + CORT $25 \mu \mathrm{g} /(\mathrm{kg} \cdot \mathrm{d})$ group and ISO + CORT $50 \mu \mathrm{g} /(\mathrm{kg} \cdot \mathrm{d}$ ) group (Figure 1C).

\section{CORT prevented a pathological change of ISO-induced myocardial injury in rats}

As shown in Figure 2, HE staining showed the approximately normal structure of myocardial tissue and cells in the control group. Myocardial tissues from ISO-induced rats demonstrated massive inflammatory cell infiltration and extensive edema and became loose compared with those of the control group. Both 25 and $50 \mu \mathrm{g} /(\mathrm{kg} \cdot \mathrm{d})$ CORT could obviously ameliorate myocardial damage induced by ISO, as shown in noticeably decreased 


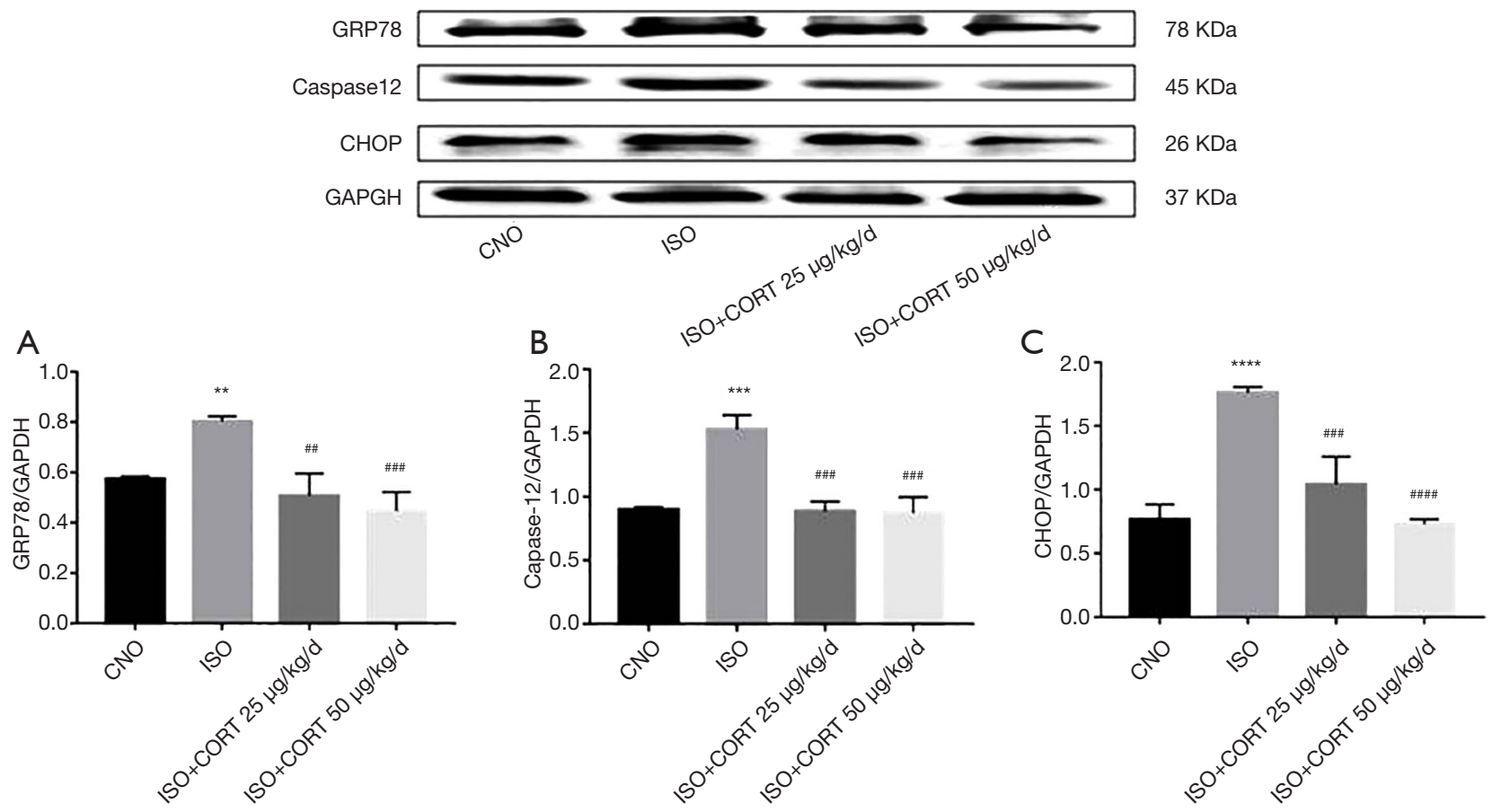

Figure 3 CORT attenuates ISO-induced endoplasmic reticulum stress in rat myocardial tissues. (A) CORT reduced the ISO-induced increase of GRP-78 protein expression in rats; (B) CORT reduced ISO-induced increase of Caspase-12 protein expression in rats; (C) CORT reduced the increase of CHOP protein expression induced by ISO in rats. Protein expression of GRP-78, Caspase-12, and CHOP was examined via Western blot and was normalized to GAPDH expression. ${ }^{* *}, \mathrm{P}<0.01,{ }^{* * *}, \mathrm{P}<0.001$, and ****, $\mathrm{P}<0.0001$ vs. CON group; ${ }^{\prime}, \mathrm{P}<0.01$, \#\#, $\mathrm{P}<0.001$, and ${ }^{\# \# \#}, \mathrm{P}<0.0001$ vs. ISO group. GRP78, glucose regulated protein 78; Capase-12, cysteine aspastic acidspecific protease 3; CHOP, CCAAT/enhancer-binding proteins (C/EBP) homologous protein; GAPDH, glyceraldehyde-3-phosphate dehydrogenase; CON, control; ISO, isoproterenol; CORT, cortistatin.

inflammatory cell infiltration in the ISO + CORT $25 \mu \mathrm{g} /(\mathrm{kg} \cdot \mathrm{d})$ group and ISO + CORT $50 \mu \mathrm{g} /(\mathrm{kg} \cdot \mathrm{d})$ group compared with the ISO group. Inflammatory cell infiltration was also observed but attenuated in the ISO + CORT $25 \mu \mathrm{g} /(\mathrm{kg} \cdot \mathrm{d})$ group. Myocardial cells in the ISO + CORT $50 \mu \mathrm{g} /(\mathrm{kg} \cdot \mathrm{d})$ group were mostly preserved or only mildly damaged.

\section{CORT attenuated the increased protein levels of GRP78, CHOP, and Caspase-12 in rats induced by ISO}

Recent studies have confirmed that GRP78, CHOP, and caspase-12 are classical markers of ERS. Compared with the control group, protein levels of GRP78, CHOP and, caspase-12 in the ISO group significantly increased $(0.80 \pm 0.02$ vs. $0.57 \pm 0.012, \mathrm{P}<0.01 ; 1.76 \pm 0.05$ vs. $0.77 \pm 0.12, \mathrm{P}<0.0001$; and $1.53 \pm 0.11$ vs. $0.90 \pm 0.02$, $\mathrm{P}<0.0001$; respectively). Different doses of CORT significantly inhibited the increased protein expression of GRP78 in rats of the ISO + CORT $25 \mu \mathrm{g} /(\mathrm{kg} \cdot \mathrm{d})$ group and ISO + CORT $50 \mu \mathrm{g} /(\mathrm{kg} \cdot \mathrm{d})$ group compared with those of the ISO group $(0.51 \pm 0.09$ or $0.45 \pm 0.08 v s$. $0.81 \pm 0.03$, both $\mathrm{P}<0.01)$. Likewise, different doses of CORT appeared to suppress the increase protein levels of CHOP and caspase-12 in rats of the ISO + CORT $25 \mu \mathrm{g} /(\mathrm{kg} \cdot \mathrm{d})$ group and ISO + CORT $50 \mu \mathrm{g} /(\mathrm{kg} \cdot \mathrm{d})$ group compared to those of the ISO group $(0.88 \pm 0.08$ or $0.87 \pm 0.12$ vs. $1.53 \pm 0.11$, both $\mathrm{P}<0.0001 ; 1.04 \pm 0.22$ or $0.73 \pm 0.04$ vs. $1.76 \pm 0.05$, both $\mathrm{P}<0.0001$; respectively). There was no statistically significant difference in the protein expression of GRP78, CHOP, and caspase-12 between the control group, ISO + CORT $25 \mu \mathrm{g} /(\mathrm{kg} \cdot \mathrm{d})$ group, and ISO + CORT $50 \mu \mathrm{g} /(\mathrm{kg} \cdot \mathrm{d}$ ) group (Figure 3).

\section{CORT inbibited the increase of LC3-II, LC3-II/I, Beclin-1 and $p 62$ in rats induced by ISO}

Previous studies have shown that autophagy is a protective 


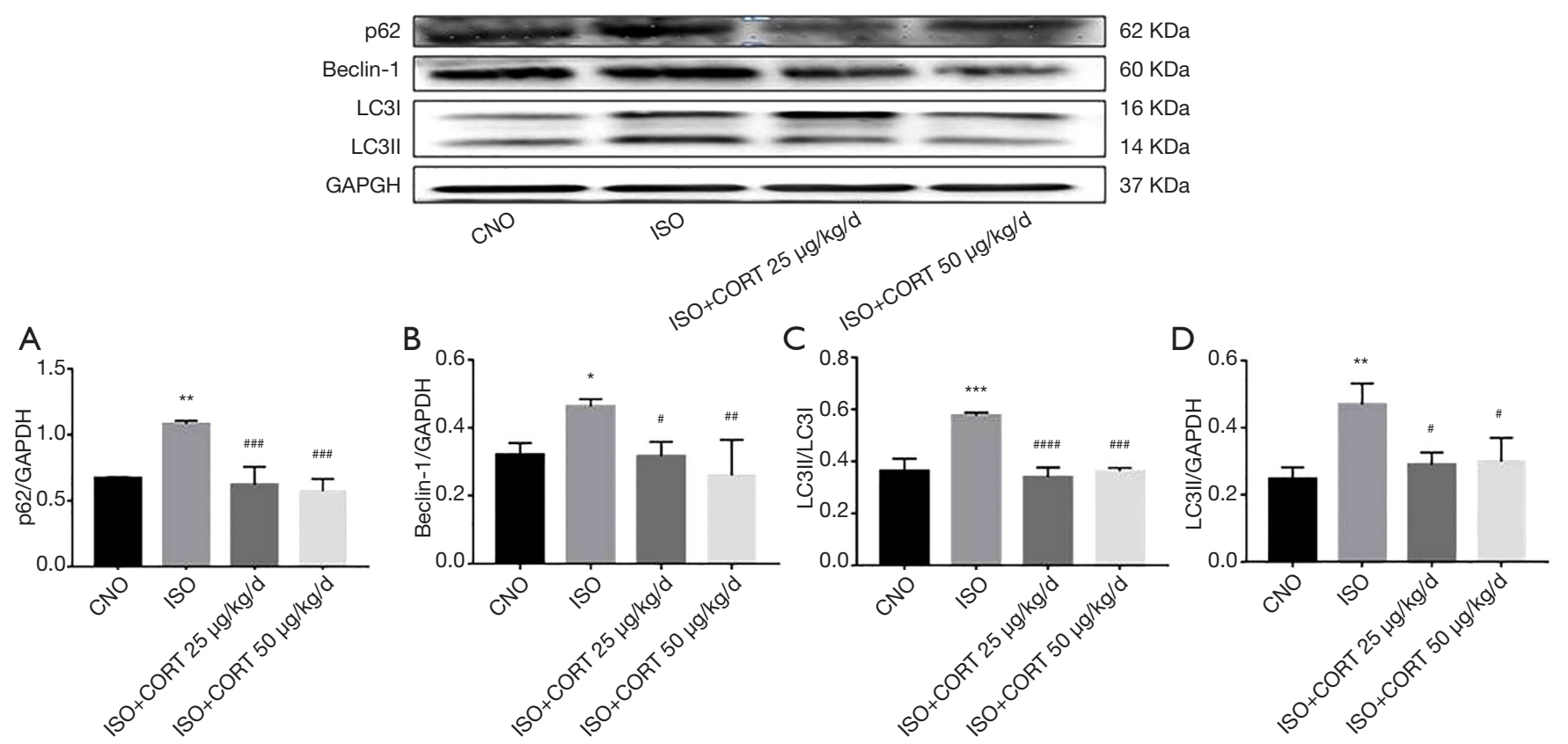

Figure 4 CORT suppresses ISO-induced autophagy in myocardial tissues of rats. (A) CORT down-regulated the ISO-induced expression of p62 protein in rats; (B) CORT down-regulated ISO-induced expression of Beclin-1 protein in rats; (C) CORT reversed the ISO-induced changes in LC3-II/I protein expression; (D) CORT reversed the ISO-induced changes in LC3-II protein expression. Protein expression of p62, Beclin-1, LC3-I, and LC3-II was examined via Western blot, while p62, Beclin-1, and LC3II were normalized to GAPDH expression. *, $\mathrm{P}<0.05,{ }^{* *}, \mathrm{P}<0.01$; **, $\mathrm{P}<0.001$ vs. CON group; ${ }^{*}, \mathrm{P}<0.05,{ }^{\# \#}, \mathrm{P}<0.01,{ }^{\# \# \#}, \mathrm{P}<0.001$, and ${ }^{\# \# \#}, \mathrm{P}<0.0001$ vs. ISO group. LC3, microtubuleassociated protein light chain 3; GAPDH, glyceraldehyde-3-phosphate dehydrogenase; CON, control; ISO, isoproterenol; CORT, cortistatin.

intracellular process that maintains cellular homeostasis, but recent studies have indicated that uncontrolled autophagy may induce cell death, thus giving rise to the concept of "autophagic cell death" (16). LC3-II and ratios of LC3-II/I, Beclin-1, and p62 are considered as autophagy markers. Compared with the control group, the LC3-II/I, LC3-II, Beclin-1, and p62 protein levels in the ISO group were dramatically increased $(1.08 \pm 0.03$ vs. $0.67 \pm 0.06$, $\mathrm{P}<0.001 ; 0.47 \pm 0.04$ vs. $0.25 \pm 0.02, \mathrm{P}<0.01 ; 0.46 \pm 0.02$ vs. $0.32 \pm 0.03, \mathrm{P}<0.05$; and $0.58 \pm 0.01$ vs. $0.36 \pm 0.05, \mathrm{P}<0.0001$, respectively). While the LC3-II/I, LC3-II, Beclin-1, and p62 levels in the ISO + CORT $25 \mu \mathrm{g} /(\mathrm{kg} \cdot \mathrm{d})$ group and ISO + CORT $50 \mu \mathrm{g} /(\mathrm{kg} \cdot \mathrm{d})$ group were significantly decreased compared to those of the ISO group $(0.62 \pm 0.03$ or $0.57 \pm 0.09$ vs. $1.08 \pm 0.03$, both $\mathrm{P}<0.001 ; 0.29 \pm 0.02$ or $0.30 \pm 0.04$ vs. $0.47 \pm 0.04$, both $\mathrm{p}<0.05 ; 0.32 \pm 0.04$ or $0.26 \pm 0.10$ vs. $0.46 \pm 0.02, \mathrm{P}<0.05, \mathrm{P}<0.01 ; 0.34 \pm 0.04$ or $0.36 \pm 0.01$ vs. $0.58 \pm 0.01$, both $\mathrm{P}<0.001$; respectively). There was no statistically significant difference in LC3-II/I, Beclin-1 and p62 protein levels between the control group, ISO + CORT
$25 \mu \mathrm{g} /(\mathrm{kg} \cdot \mathrm{d})$ group, and ISO + CORT $50 \mu \mathrm{g} /(\mathrm{kg} \cdot \mathrm{d})$ group (Figure 4).

\section{Discussion}

In this study, the administration of CORT alleviated myocardial injury in rats induced by ISO, as shown by its reduction of the increased activities in LDH and CK$\mathrm{MB}$, and by its alleviating of the pathological myocardial damage and inflammatory cell infiltration. Moreover, we demonstrated that this cardioprotection of CORT was likely mediated via reducing lipid peroxidation, ERS, and autophagy.

ISO is a beta-adrenergic receptor agonist that has been widely used to induce experimental animal models of myocardial damage, resulting in morphological and biochemical changes in the heart similar to the change in humans (17). In clinical practice, $\mathrm{LDH}$ and CK-MB are released into the blood during myocardial injury, and there is a significantly positive correlation between elevated 
$\mathrm{LDH}$ and CK-MB and ischemic myocardial injury (18). Therefore, $\mathrm{LDH}$ and CK-MB are often used as indicators to assess the extent of ischemic heart damage. In the present study, the levels of LDH and CK-MB were significantly elevated in the ISO group when compared to the levels in the control group. Moreover, myocardial tissues were infiltrated by massive inflammatory cells, and became loose, and had obvious myocardial cell rupture in rats of the ISO group compared to the control group. These data indicate that an experimental rat model of acute myocardial injury was established, which was consistent with the model of myocardial ischemic injury induced by ISO by Garg et al. and Akila et al. (19,20). Moreover, we demonstrated that different doses of CORT could reduce the ISOinduced increase of $\mathrm{LDH}$ and $\mathrm{CK}-\mathrm{MB}$ and pathological morphological changes in the rat in a dose-independent manner. This provides the first in vivo evidence that CORT protects myocardia from ISO-induced injury.

Oxidative stress and lipid peroxidation are involved in the development of myocardial injury. In this study, we found that the serum MDA level was significantly higher in the ISO group than that in the control group. It has been shown that ISO can increase myocardial contraction and oxygen demand, resulting in electron leakage in the respiratory chain. These free electrons interact with molecular oxygen to create reactive oxygen species (ROS), further oxidizing elements of the cells, including proteins, DNA, and membrane lipids, directly damaging the myocardium. Suchal et al. also reported that antioxidant enzyme levels were significantly reduced, while MDA levels were elevated in ISO treated rats (15). Our further study indicates that different doses of CORT could prevent the increased levels of serum MDA in rats induced by ISO, suggesting that inhibition of CORT on myocardial injury caused by ISO was associated with reducing lipid peroxidation. However, this underlying mechanism remains to be further studied.

A wealth of evidence has convincingly demonstrated that ERS plays a crucial role in the development of the cardiovascular disease, including myocardial infarction (21), myocardial ischemia/reperfusion (I/R) injury (22), heart failure, and other conditions (23). The endoplasmic reticulum (ER) is a dynamic organelle that is essential for maintaining cellular homeostasis. Under stressful situations, such as ischemia, hypoxia, oxidative stress, and changes of intracellular $\mathrm{Ca}^{2+}$ concentrations, the ER environment is compromised, which consequently leads to the accumulation of unfolded proteins, which is called ERS (24). In this study, we found that the expression classical ERS markers like GRP78, caspase-12, and CHOP protein in the myocardial tissue of the ISO group was significantly increased compared with the control group, while the expression of GRP78, caspase-12, and CHOP protein were significantly lower in the ISO + CORT group than those in ISO group, indicating that CORT might attenuate ISOinduced myocardial injury in rats by inhibiting ERS. It has been reported that ERS initiates its signaling pathways by activating 3 transmembrane effector proteins: protein kinase RNA-like ER kinase (PERK), inositol-requiring protein-1 (IRE-1), and activating transcription factor 6 (ATF6) (25), and thus participates in cardiovascular diseases. However, the regulating role of ERS signaling in the cardioprotection by CORT remains unclear and needs to be further elucidated.

Autophagy plays a pivotal role in regulating cellular homeostasis by eliminating old or unfolded proteins, longlived organelles, and intracellular pathogens in response to starvation and various stresses (26). An increasing number of studies have revealed that autophagy is a critical player in the development of the cardiovascular disease, including the development of atherosclerosis (27), diabetic cardiomyopathy (28), cardiac (I/R) (29), and heart failure (30). There is ongoing controversy about the role of autophagy in cardiovascular disease (pro-survival versus pro-death). Autophagy is widely acknowledged to be a cytoprotective response to an overload of unfolded or misfolded proteins, and uncontrolled autophagy, under extreme or long-term stress, contributes to cardiac cell death (31). In this study, the expression of LC3-II, Beclin-1, and p62 protein, and the ratio of LC3-II/I in the myocardial tissue of the ISO group were significantly higher than those in the control group, indicating that ISO may activate the autophagy process of myocardial tissue in rats. The expression of LC3-II, Beclin-1, and p62 protein, and the ratio of LC3-II/I in the myocardial tissue of the ISO + CORT group were significantly lower than those in the ISO group, indicating that CORT may inhibit myocardial autophagy activity induced by ISO in rats.

Notably, some studies have shown that lipid oxidation products contribute to triggering ERS. In particular, ERS activation has been demonstrated in endothelial cells exposed to oxysterols and oxidized low-density lipoprotein (ox-LDL) $(32,33)$. Proteins are much more susceptible to oxidative stress than fat and DNA (34). It has been confirmed that the activation of IRE1 $\alpha$, PERK, and ATF6 and the subsequent activation of CHOP, GRP78, and GRP94 are associated with ox-LDL treatment $(35,36)$. It is worth mentioning that ox- 
LDL can also activate autophagy (36). Even so, the specific molecular interactions of ERS, autophagy, and lipid oxidation in CORT's inhibition of myocardial injury induced by ISO remain to be further clarified.

In summary, the present study is first to demonstrate that CORT may attenuate acute myocardial injury in rats induced by ISO, which is likely mediated by CORT's reduction of lipid peroxidation and inhibition of ERS and autophagy. These provide rational evidence for CORT as a novel target for the prevention and treatment of myocardial injury and its related diseases.

\section{Acknowledgments}

Funding: This research was supported by National Natural Science Foundation of China (Grant No. 81200235, 81800419 and 81200143), Research Foundation of Education Bureau of Heilongjiang Province, China (Grant No. 12541338), Provincial youth science fund of Heilongiiang (Grant No. QC2017104) and Foundation of the First Affiliated Hospital of Harbin Medical University, Harbin, China (Grant No. 2015B005, 2019M08). The funders had no role in study design, data collection and analysis, decision to publish, or preparation of the manuscript.

\section{Footnote}

Conflicts of Interest: The authors have no conflicts of interest to declare.

Ethical Statement: The authors are accountable for all aspects of the work in ensuring that questions related to the accuracy or integrity of any part of the work are appropriately investigated and resolved. Rats received humane care and all experimental protocols complied with Animal Management Rule of the People's Republic of China (Ministry of Health, P. R. China, document no. $55,2001)$, and Animal Care Committee of Harbin Medical University Health Science Center.

Open Access Statement: This is an Open Access article distributed in accordance with the Creative Commons Attribution-NonCommercial-NoDerivs 4.0 International License (CC BY-NC-ND 4.0), which permits the noncommercial replication and distribution of the article with the strict proviso that no changes or edits are made and the original work is properly cited (including links to both the formal publication through the relevant DOI and the license).
See: https://creativecommons.org/licenses/by-nc-nd/4.0/.

\section{References}

1. Kim JO, Park JH, Kim T, et al. A novel system-level approach using RNA-sequencing data identifies miR$30-5 p$ and miR-142a-5p as key regulators of apoptosis in myocardial infarction. Sci Rep 2018;8:14638.

2. Wu D, Wang J, Wang H, et al. Protective roles of bioactive peptides during ischemia-reperfusion injury: From bench to bedside. Life Sci 2017;180:83-92.

3. Liang J, Bai Y, Chen W, et al. Cortistatin, a novel cardiovascular protective peptide. Cardiovasc Diagn Ther 2019;9:394-9.

4. Markovics A, Szoke É, Sándor K, et al. Comparison of the Anti-inflammatory and Anti-nociceptive Effects of Cortistatin-14 and Somatostatin-14 in Distinct In Vitro and In Vivo Model Systems. J Mol Neurosci 2012;46:40-50.

5. Yan S, Li M, Chai H, et al. TNF-alpha decreases expression of somatostatin, somatostatin receptors, and cortistatin in human coronary endothelial cells. J Surg Res 2005;123:294-301.

6. Wang Y, Zhang X, Gao L, et al. Cortistatin exerts antiproliferation and antimigration effects in vascular smooth muscle cells stimulated by Ang II through suppressing ERK1/2, p38 MAPK, JNK and ERK5 signaling pathways. Ann Transl Med 2019;7:561.

7. Duran-Prado M, Morell M, Delgado-Maroto V, et al. Cortistatin inhibits migration and proliferation of human vascular smooth muscle cells and decreases neointimal formation on carotid artery ligation. Circ Res 2013;112:1444-55.

8. Delgado-Maroto V, Falo CP, Forte-Lago I, et al. The neuropeptide cortistatin attenuates experimental autoimmune myocarditis via inhibition of cardiomyogenic $\mathrm{T}$ cell-driven inflammatory responses. Br J Pharmacol 2017;174:267-80.

9. Delgado-Maroto V, Benitez R, Forte-Lago I, et al. Cortistatin reduces atherosclerosis in hyperlipidemic ApoE-deficient mice and the formation of foam cells. Sci Rep 2017;7:46444.

10. Liu $\mathrm{Y}, \mathrm{Lin} \mathrm{F}, \mathrm{Fu} \mathrm{Y}$, et al. Cortistatin inhibits calcification of vascular smooth muscle cells by depressing osteoblastic differentiation and endoplasmic reticulum stress. Amino Acids 2016;48:2671-81.

11. Liu Y, Lin F, Fu Y, et al. Cortistatin inhibits arterial calcification in rats via GSK3 $\beta / \beta$-catenin and protein kinase $\mathrm{C}$ signalling but not c-Jun $\mathrm{N}$-terminal kinase signaling. Acta Physiol (Oxf) 2018;223:e13055. 
12. Zhang B, Liu Y, Sui YB, et al. Cortistatin inhibits NLRP3 inflammasome activation of cardiac fibroblasts during sepsis. J Card Fail 2015;21:426-33.

13. Zhang B, Liu Y, Zhang JS, et al. Cortistatin protects myocardium from endoplasmic reticulum stress induced apoptosis during sepsis. Mol Cell Endocrinol 2015;406:40-8.

14. Shi ZY, Liu Y, Dong L, et al. Cortistatin Improves Cardiac Function After Acute Myocardial Infarction in Rats by Suppressing Myocardial Apoptosis and Endoplasmic Reticulum Stress. J Cardiovasc Pharmacol Ther 2017;22:83-93.

15. Suchal K, Malik S, Gamad N, et al. Kampeferol protects against oxidative stress and apoptotic damage in experimental model of isoproterenol-induced cardiac toxicity in rats. Phytomedicine 2016;23:1401-8.

16. Denton D, Kumar S. Autophagy-dependent cell death. Cell Death Differ 2019;26:605-16.

17. Clements P, Brady S, York M, et al. Time course characterisation of serum cardiac troponins, heart fatty acid Binding protein and morphologic findings with isoproterenol-induced myocardial injury in the rat. Toxicol Pathol 2010;38:703-14.

18. Derbali A, Mnafgui K, Affes M, et al. Cardioprotective effect of linseed oil against isoproterenol-induced myocardial infarction in Wistar rats: a biochemical and electrocardiographic study. J Physiol Biochem 2015;71:281-8.

19. Garg S, Malhotra RK, Khan SI, et al. Fisetin attenuates isoproterenol-induced cardiac ischemic injury in vivo by suppressing RAGE/NF- $\kappa \mathrm{B}$ mediated oxidative stress, apoptosis and inflammation. Phytomedicine 2019;56:147-55.

20. Akila P, Asaikumar L, Vennila L. Chlorogenic acid ameliorates isoproterenol-induced myocardial injury in rats by stabilizing mitochondrial and lysosomal enzymes. Biomed Pharmacother. Biomed Pharmacother 2017;85:582-91.

21. Xu Y, Wu L, Chen A, et al. Protective Effects of Olive Leaf Extract on Acrolein-Exacerbated Myocardial Infarction via an Endoplasmic Reticulum Stress Pathway. Int J Mol Sci 2018. doi: 10.3390/ijms19020493.

22. Wu H, Ye M, Yang J, et al. Modulating endoplasmic reticulum stress to alleviate myocardial ischemia and reperfusion injury from basic research to clinical practice: A long way to go. Int J Cardiol 2016;223:630-1.

23. Steiger D, Yokota T, Li J, et al. The serine/threonineprotein kinase/ endoribonuclease IRE1 $\alpha$ protects the heart against pressure overload-induced heart failure. J Biol Chem 2018;293:9652-61.

24. Wang S, Binder P, Fang Q, et al. Endoplasmic reticulum stress in the heart: The insights into mechanisms and drug targets. Br J Pharmacol 2018;175:1293-304.

25. Zhang C, Syed TW, Liu R, et al. Role of Endoplasmic Reticulum Stress, Autophagy, and Inflammation in Cardiovascular Disease. Frontiers in Cardiovascular Medicine 2017;4:29.

26. Wang Y, Li YB, Yin JJ, et al. Autophagy regulates inflammation following oxidative injury in diabetes. Autophagy 2013;9:272-7.

27. Grootaert MOJ, Moulis M, Roth L, et al. Vascular smooth muscle cell death, autophagy and senescence in atherosclerosis. Cardiovasc Res 2018;114:622-34.

28. Kobayashi S, Liang Q. Autophagy and mitophagy in diabetic cardiomyopathy. Biochim Biophys Acta 2015;1852:252-61.

29. Ma S, Wang Y, Chen Y, et al. The role of the autophagy in myocardial ischemia/reperfusion injury. Biochim Biophys Acta 2015;1852:271-6.

30. Pawlak A, Bil J, Gil RJ. The regulatory mechanisms of protein expression in heart failure patients' cardiomyocytes. The ubiquitin-proteasome system. Autophagy. Kardiol Pol 2012;70:1170-6.

31. Abdellatif M, Sedej S, Madeo F, et al. Cardioprotective effects of autophagy induction in sepsis. Ann Transl Med 2018;6:S61.

32. Hong D, Bai YP, Gao HC, et al. Ox-LDL induces endothelial cell apoptosis via The LOX-1-dependent endoplasmic reticulum stress pathway. Atherosclerosis 2014;235:310-7.

33. Miyoshi N, Iuliano L, Tomono S, et al. Implications of cholesterol autoxidation products in the pathogenesis of inflammatory diseases. Biochem Biophys Res Commun 2014;446:702-8.

34. Corcoran A, Cotter TG. Redox regulation of protein kinases. FEBS J 2013;280:1944-65.

35. Di M, Wang L, Li M, et al. Dickkopf1 destabilizes atherosclerotic plaques and promotes plaque formation by inducing apoptosis of endothelial cells through activation of ER stress. Cell Death Dis 2017;8:e2917.

36. Yang J, Yu J, Li D, et al. Store-operated calcium entryactivated autophagy protects EPC proliferation via the CAMKK2-MTOR pathway in ox-LDL exposure. Autophagy 2017;13:82-98.

Cite this article as: Chen W, Liang J, Fu Y, Jin Y, Yan R, Chi J, Liu W, Liu Y, Yin X. Cardioprotection of cortistatin against isoproterenol-induced myocardial injury in rats. Ann Transl Med 2020;8(6):309. doi: 10.21037/atm.2020.02.93 